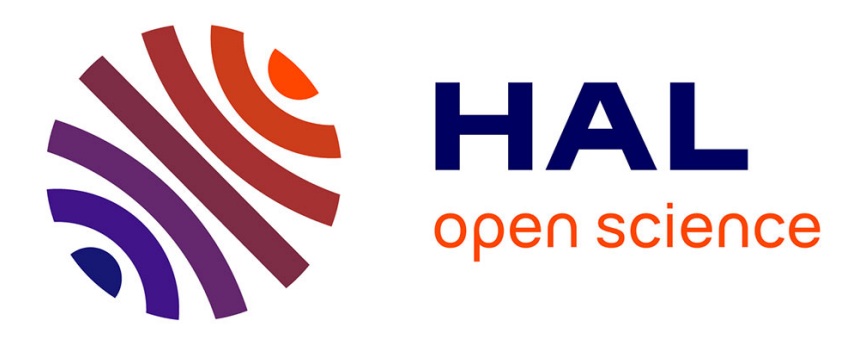

\title{
Effects of Strain Rate and Temperature in Forming Processes of Metals
}

\author{
K. Osakada
}

\section{To cite this version:}

K. Osakada. Effects of Strain Rate and Temperature in Forming Processes of Metals. Journal de Physique IV Proceedings, 1997, 07 (C3), pp.C3-XXXVII-C3-XLIV. 10.1051/jp4:1997302 . jpa00255375

\section{HAL Id: jpa-00255375 https://hal.science/jpa-00255375}

Submitted on 1 Jan 1997

HAL is a multi-disciplinary open access archive for the deposit and dissemination of scientific research documents, whether they are published or not. The documents may come from teaching and research institutions in France or abroad, or from public or private research centers.
L'archive ouverte pluridisciplinaire HAL, est destinée au dépôt et à la diffusion de documents scientifiques de niveau recherche, publiés ou non, émanant des établissements d'enseignement et de recherche français ou étrangers, des laboratoires publics ou privés. 


\title{
Effects of Strain Rate and Temperature in Forming Processes of Metals
}

\author{
K. Osakada
}

Faculty of Engineering Science, Osaka University, Machikaneyama 1-3, Toyonaka, Osaka, 560, Japan

\begin{abstract}
In metal forming processes, the behavior of the metals undergoing large plastic deformation is affected by the dynamic or sirain rate effects of the material and inertia effect. Since both of the material and mechanical effects are correlated each other in the forming processes, they are effectively treated by the finite element methods which can take account of surain rate effect.

Usually the effect of strain rate on the flow stress of metals is not significant at low temperature and becomes significant as the temperature rises. When the strain rate effect is significant, the forming pressure is lowered by decreasing the strain rate. In isothermal forming, in which the tools are heated to the same temperature as the billet in order not to cool down the billet, a low forming velocity is employed to reduce the forming load.

The deformed shape of the material is also affected by the strain rate effect. In general, deformation is dispersed when the strain rate effect is significant. This effect is most utilized in superplastic forming in which occurence of necking is avoided and a very large deformation is attained. Since this phenomenon is usually caused at a very low strain rate, it is desirable to develop metals which exhibit significant strain rate effects at high strain rate. As an example, a superplastic aluminium alloy which causes a significant strain rate effect at a high strain rate is introduced.
\end{abstract}

\begin{abstract}
Résumé : Au cours des procédés de mise en forme, les métaux subissant de fortes déformations plastiques sont soumis aux effets des grandes vitesses de déformation et aux effets d'inertie. Ces effets étant dépendants les uns des autres, on peut utiliser les méthodes de simulation aux éléments tinis pour reproduire les états déformés à grande vitesse.

En général, on constate que ce n'est que lorsque la température augmente significativement que l'effet de la vitesse de déformation devient non négligeable. La pression exercée lors du formage est alors diminuée par la chute de la vitesse de deformation.

En condition de formage isotherme, l'outil est porté a la même température que la billette atĩn de ne pas retroidir celle-ci, dans de telles conditions on utilisera une faible vitesse de formage de manière à réduire la charge appliquée.

La forme finale de la piece sera elle aussi influencée par la vitesse de deformation. Les plus fortes dispersions sont constatées par les fortes vitesses. Cet effet est largement exploité dans le procédé de formage superplastique où l'écoulement plastique homogène est obtenu pour de très fortes valeurs d'écoulement plastique.

Compte tenu que ce phénomène n'est exploité qu'à basse vitesse de déformation, on comprend l'intérêt de développer des métaux pour lesquels cette propriêté serait obtenue à grande vitesse de déformation.

C'est dans cet objectif que nous présentons ce travail réalisé sur un alliage d'aluminium à comportement superplastique et présentant l'effet de vitesse de déformation aux grandes vitesses.
\end{abstract}

\section{INTRODUCTION}

In metal forming processes such as rolling, forging, extrusion, wire drawing and sheet metal forming, the flow stress of the metal is a key factor for successful operation. The forming pressure and the load are directly related to the flow stress, and therefore a lower flow stress is desirable in most of the forming operations. Since the flow stress is usually reduced with temperature, a high working temperature is beneficial to carry out the operation with a low load or pressure.

The strain rate sensitivity of flow stress is significant at high temperatures, and this brings about difficulties in accurate estimation of the flow stress needed for automatic control in high speed hot rolling. Since the conventional material tests are too slow, high peed compression tests were performed to collect flow curves as basic data of rolling.

The dimensional accuracy of the product made at a high temperature is not good because of formation of thick oxide layer and dimensional change in the process of cooling. So that finishing operations under the cold (room temperature) condition are often carried out after hot forming to attain close dimensional tolerance of the product. Since the flow stress of a practical metal is extremely high at room temperature, the tool life is shortened by fatigue and wear under the high contacting pressure. Thus, an exact estimation of the pressure using a realistic flow curve is essential for designing the process and the tools in cold metal forming.

Precision forming under cold and warm (heated below recrystalization temperature) conditions has become indispensable for economical production of automobile parts by avoiding subsequent machining. At low temperatures the flow stress is sensitive to the 
temperature but is not affected by strain rate so much. It is known that almost all the forming energy is converted into heat and the temperature of the deforming billet is heightened by 300 $-500^{\circ} \mathrm{C}$ after a large equivalent strain of $2.0-3.0$ for steels. This temperature rise, in turn, changes the flow stress; the flow stress at a large strain is reduced by the temperature rise.

Forming limit and occurrence of various defects in metal forming are also related to the flow stress characteristics. If a material exhibits sensitive work-hardening, the forming limit is extended in sheet forming and wire drawing because the work-hardened part after plastic deformation can support a large forming force. A similar effect is observed when the metal is strain rate sensitive. If the flow stress changes significantly with strain rate, uniform elongation is very large, e.g., $100-1000 \%$, and this phenomenon is called "superplasticity".

For the analysis of metal forming the flow stress of the material is the fundamental value, but different expressions of flow stress are required depending on the analytical method. The slab method was developed in the 1930 s for calculating the forming load, and the upper bound method became to be applied to metal forming in the 1960s. From the $1980 \mathrm{~s}$ the finite element method spread rapidly for predicting not only the load but also the distributions of stress, strain and temperature in the material. In this paper, some studies of strain rate effect in metal forming are explained in connection with the analytical methods.

\section{CLASSICAL ANALYSIS AND FLOW STRESS MEASUREMENT}

In the analyses of metal forming by the slab and upper bound methods, the flow stress $\bar{\sigma}(\bar{\varepsilon}, \dot{\bar{\varepsilon}}, T)$, which is essentially affected by equivalent strain $\bar{\varepsilon}$, strain rate $\dot{\bar{\varepsilon}}$ and temperature $T$, is simplified to be constant $Y$ : non-hardening and strain rate insensitive. The forming load $P$ and forming pressure $p$ are expressed as

$$
P=A p=C A Y
$$

where $A$ is the projected area of the billet to the direction of loading and $C$ is the constraining factor which is dependent on the shape of the tool and other geometrical conditions. This equation suggests that the forming load and pressure are in proportion to the flow stress. In the classical analyses, work-hardening is approximately taken into account by employing a flow stress value at a strain calculated with some methods, e.g. average strain in the deforming region. The effects of strain rate and temperature are considered by using a flow stress for the estimated strain rate and temperature.

The strain rates in practical metal forming processes drop in the range from 1 to $500 / \mathrm{sec}$ and the strains are greater than 1.0 . Since the strain rates attained by the material testing machines are lower than $0.1 / \mathrm{sec}$ and uniform strain in tension test is less than 0.3 , they are not adequate for determining the flow stress in metal forming. The flow curves at high strain rates and large strains were measured with high speed compression tests on actual forming machines.

Fig.1 [1] shows an arrangement of flow stress measurement on a high speed hammer driven by compressed air. The highest speed of the hammer is $25 \mathrm{~m} / \mathrm{sec}$. Since a heated compression specimen tends to be partially cooled before the onset of compression through the contact with the lower tool, the specimen was suspended by

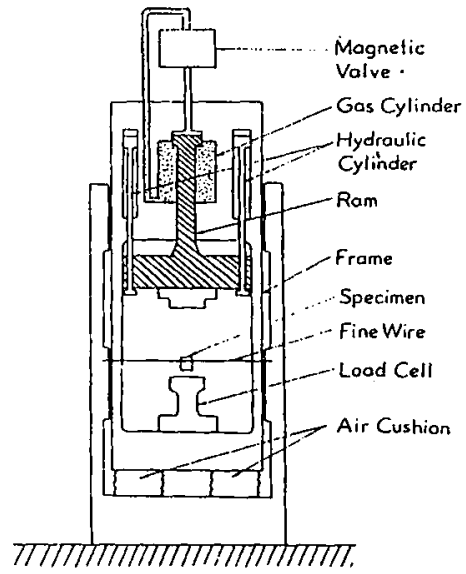

Fig. 1 Selematic Illustration of High Speed Hammer 
fine wires in the space where the upper and the lower tools collide simultaneously with the specimen.

Fig. 2 shows the flow curves of $0.35 \%$ carbon steel at room temperature under various strain rates. The tests for the low strain rates were carried out on a hydraulic press.

The flow stress is often expressed by :

$$
\vec{\sigma}=f(\bar{\varepsilon}, T)\left(\dot{\bar{\varepsilon}} / \dot{\bar{\varepsilon}}_{0}\right)^{m}
$$

where $\dot{\bar{\varepsilon}}_{0}$ is reference strain rate for nondimensional treatment, and the value $m$ is call "strain rate sensitivity index". In Fig.3 are shown the flow curves of $0.35 \%$ carbon steel under a high strain rate of $450 / \mathrm{sec}$ at various temperatures. As the temperature rises, the flow stress decreases up to $400^{\circ} \mathrm{C}$, and then increases with temperature from 400 to $600^{\circ} \mathrm{C}$.

In Fig. 4 the flow stress measured on the hammer $(450 / \mathrm{sec})$ is compared with the flow stress on the hydraulic press $(0.1 / \mathrm{sec})$ at

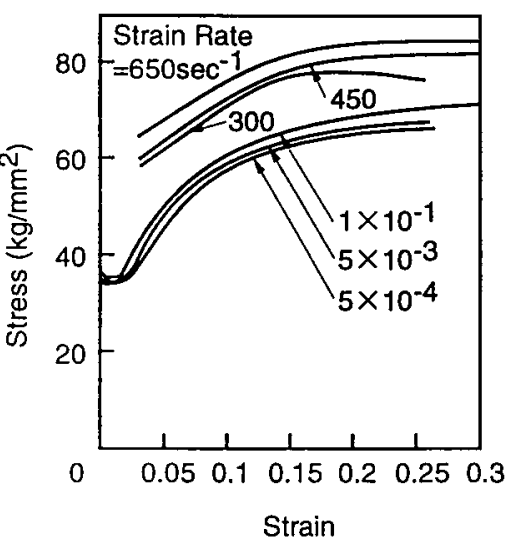

Fig.2 Flow curves of $0.35 \% \mathrm{C}$ steel at various strain rates a strain of 0.3 . With the 4500 times change in strain rate, the flow stress is changed about 2.5 times $(m=0.11)$ at $1200^{\circ} \mathrm{C}$ and about 1.2 times $(m=0.025)$ at room temperature. The great sensitivity to strain rate at high temperatures can be attributed to the occurrence of recrystallization and recovery. The peak of the flow stress due to dynamic strain aging shifts from about $350^{\circ} \mathrm{C}$ to $600^{\circ} \mathrm{C}$ when the strain rate is changed from $0.1 / \mathrm{sec}$ to $450 / \mathrm{sec}$. In this temperature range, the flow stress decreases as the strain rate increases.

A similar irregular change of flow stress with temperature appears owing to phase transformation. Fig.5 shows the dependence of flow stresses of ferritic and martensitic $13 \mathrm{Cr}$ stainless steels. In the case of martensitic steel, the flow stress increases with temperature in $800-900^{\circ} \mathrm{C}$ where the phase changes from $\alpha$ to $\gamma$.

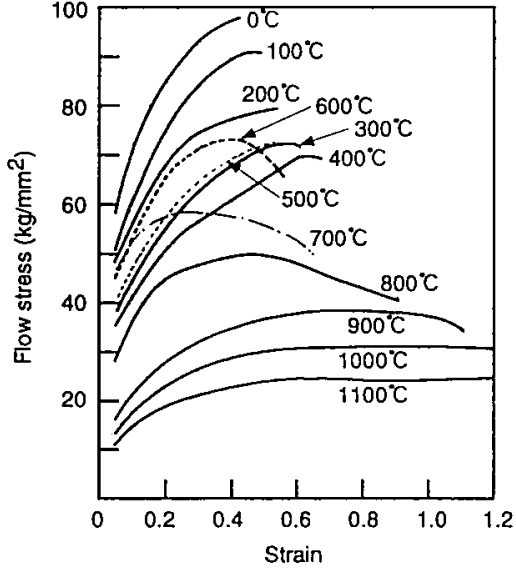

Fig.3 Flow curves of $0.35 \%$ carbon steel at various temperatures at $450 / \mathrm{sec}$

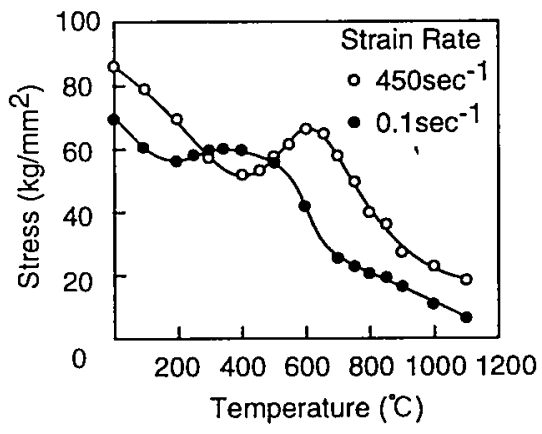

Fig.4 Effect of strain rate on flow stresstemperature curve of $0.35 \%$ carbon steel at strain $=0.2$

(shif of peak due to dynamic aging) 
By measuring the flow curves at various initial temperatures in high speed deformation, which can be considered to be adiabatic, the flow curves under constant temperatures can be estimated. Fig. 6 shows the flow curves of $0.35 \%$ carbon steel from 650 to $850^{\circ} \mathrm{C}$. The solid curves are measured at the displayed initial temperatures. The temperature during deformation is calculated by assuming that the deformation energy is completely converted into heat. The broken curves are obtained by connecting the measured flow curves at the same calculated temperatures. It can be seen that the adiabatic and isothermal curves apart each other at the strains greater than 0.2 .

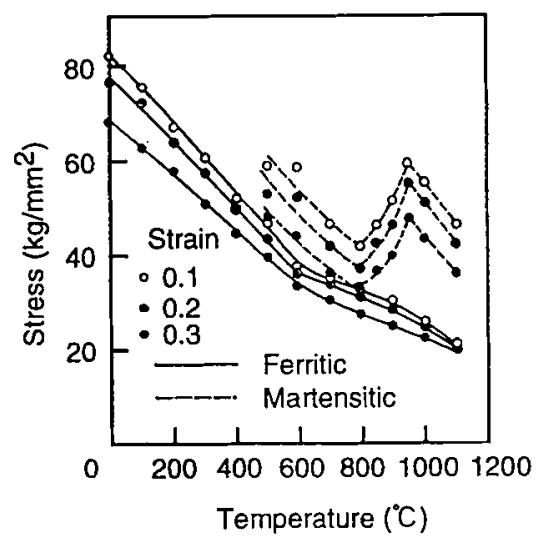

Fig.5 Flow stress-temperature curves for ferritic and martensitic $13 \mathrm{Cr}$ steels at $450 / \mathrm{sec}$

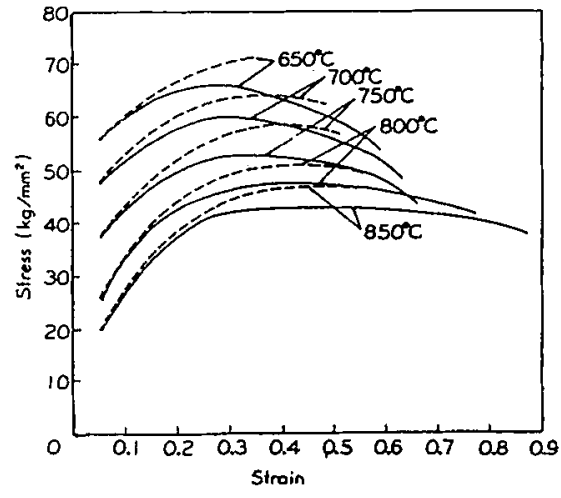

Fig.6 Adiabatic and isothermal flow curves of $0.35 \%$ C steel at $450 / \mathrm{sec}$ Solid line: Adiabatic Broken line: Isothermal

\section{FINITE ELEMENT METHOD FOR RATE SENSITIVE MATERIAL}

\subsection{Outline of Formulation}

In the stepwise calculation by the finite element method (FEM), the strain increment of a point in the billet is summed up, and the distribution of equivalent strain is calculated. Thus, the work-hardening characteristics can be taken into account by providing each element with a flow stress value corresponding to the calculated strain. To be used in the FEM, the flow stress is desirably expressed in a form of equation using strain, strain rate and temperature as variables.

Consider a continuum with a volume, $V$, which undergoes large plastic deformation. The surface $S$ is composed of $S v$ and $S_{T}$, where $S v$ is the surface on which the velocity is prescribed and $S_{T}$ is the surface on which the external traction $t_{i}$ is prescribed. In the case of a strain rate sensitive material, the flow stress itself is not known beforehand because the strain rate is to be obtained as the result of calculation. Thus, instead of assuming flow stress distribution, the distribution of the term of equivalent strain and temperature, $f(\bar{\varepsilon}, T)$, is given because they are known, and the term of strain rate is left unknown.

The correct solution satisfies the equilibrium of stress and the velocity boundary conditions. In the case of incompressible material, the velocity field satisfies the condition of volume constancy as well. Let us consider a series of solutions which satisfy only the velocity conditions: kinematically admissible velocity fields. Among the kinematically admissible velocity fields, the correct solution minimizes the following functional $\Phi$ : 


$$
\Phi=\int_{V}\left[\int_{0}^{\dot{\varepsilon}} \bar{\sigma} d \dot{\bar{\varepsilon}}\right] d V-\int_{S_{T}} \bar{t}_{i} v_{i} d S=\int_{V} f(\bar{\varepsilon}, T) \dot{\bar{\varepsilon}}_{0}^{-m}(m+1)^{-1} \dot{\bar{\varepsilon}}^{m+1} d V-\int_{S_{T}} \bar{t}_{i} v_{i} d S
$$

The first term on the right-hand side expresses the energy function, and the second term expresses the potential against surface traction.

\subsection{Finite Element Discretization}

In the case of the finite element method, the deforming body is discretized into elements and the velocities $u_{i}$ of the nodal points are the unknown variables. A velocity component $v_{i}$ at an arbitrary point is expressed by interpolating the nodal velocities of the element in which the point exists. The strain rate components in the element is expressed as:

$$
\{\dot{\varepsilon}\}=\{B\}\{u\}
$$

Since the equivalent strain rate $\overline{\bar{\varepsilon}}$ is a function of the strain rate components, it can be expressed in terms of the nodal velocities and then eq.(3) is expressed by the nodal velocities.

The stationary condition of the functional $\Phi$ is derived by partially differentiating it with each nodal velocity component $u_{i}$ and equating to zero.

$$
\frac{\partial \Phi}{\partial u_{i}}=q_{i}\left(u_{1}, u_{2}, \cdots, u_{N}\right)=0
$$

where $N$ is the total number of the nodal velocities. The nodal velocities are obtained by solving these nonlinear equations. This formulation was extended to finite deformation and impact deformation in which inertia effect cannot be neglected.

\subsection{Stress Calculation}

If the material is incompressible in plastic deformation, the hydrostatic stress cannot be calculated directly from the strain rate distribution. To avoid this problem, the yield criterion is approximated as follows [5]:

$$
\bar{\sigma}=\sqrt{(3 / 2) \sigma_{i j}^{\prime} \sigma_{i j}^{\prime}+g \sigma_{m}^{2}},
$$

where $\sigma_{i j}^{\prime}$ is the deviatoric stress tensor, $g$ is a small positive constant and $\sigma_{m}$ is the hydrostatic stress. The hydrostatic stress is directly related with the volumetric strain rate.

\subsection{Examples}

The above explained FEM can be extended to various forming problems. Fig. 7 and Fig. 8 show, respectively, necking formation in the tension test specimen with unstable deformation [2], and propagation of deforming zone in impact of an aluminum block to a rigid wall where the inertia effect cannot be neglected [3].

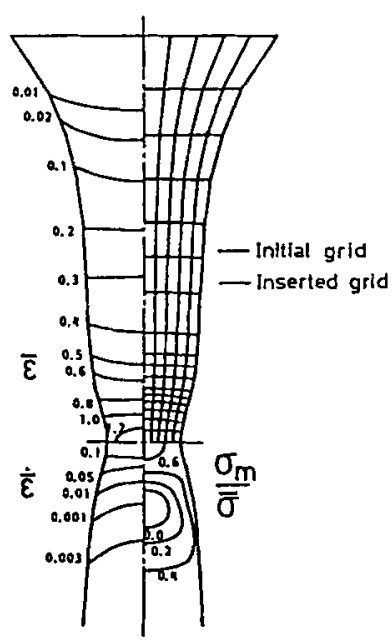

Fig.7 Distribution of strain, strain rate and hydrostatic stress in necked area of tension test specimen 


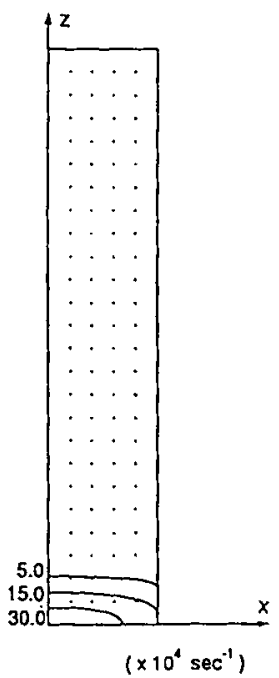

(a) Initial step

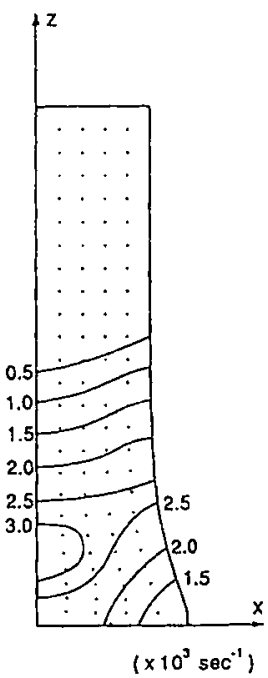

(b) 90 th step

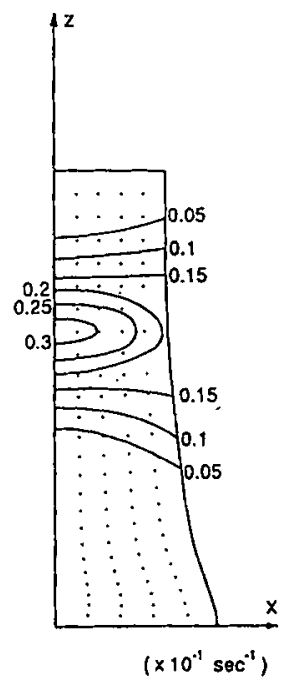

(c) Final ( 187 th ) step

Fig.8 Strain rate distribution of $5 \times 5 \times 25 \mathrm{~mm}$ aluminum block after impact to rigid wall Impact speed $=150 \mathrm{~m} / \mathrm{sec}$, Time increment $=1 \mu \mathrm{sec} / \mathrm{step}$

\section{SUPERPLASTICITY}

\subsection{Strain Rate Sensitivity and Elongation}

Superplasticity is known to appear when the flow stress is significantly affected by strain rate, i.e., strain rate sensitivity index $m$ is large. When a material is rate sensitive, the area deforming with a relatively high strain rate has a great flow stress, and further concentration of strain cannot occur, and as a result deforming region diffuses. In tension test and sheet metal forming a large uniform strain is attained.

Fig.9 [4] shows the effects of strain rate on the flow stress and the total elongation of commercial aluminum bronze deformed at temperatures from 1048 to $1123 \mathrm{~K}$. The flow stress increases markedly with strain rate between $10^{-3}$ and $10^{-2} / \mathrm{sec}$. By the increase of the strain rate from $10^{-3} / \mathrm{sec}$ to $10^{-2} / \mathrm{sec}$, the flow stress increases by $2-5$ times. The strain rate sensitivity index $m$ is $0.4-0.6$ and the maximum elongation reaches 400 to $600 \%$.

In the 1970s, this phenomenon was studied extensively with $\mathrm{Zn}$ alloys such as $\mathrm{Zn}-\mathrm{Al} 22$ (Zinc with $22 \% \mathrm{Al}$ and $0.5 \% \mathrm{Cu}$ ), and aluminum alloys such as $\mathrm{Al}-4 \mathrm{Cu}-0.5 \mathrm{Zr}$. It was found that almost all the

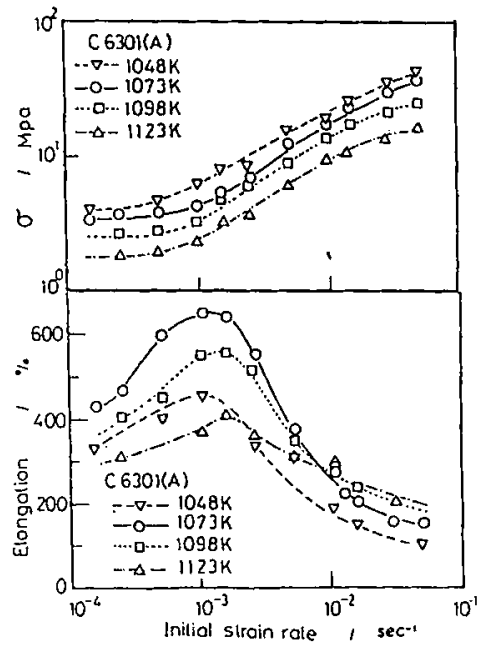

Fig.9 Effect of strain rate on total elongation and $m$-value of superplastic aluminum bronze 
metals exhibit large elongation at elevated temperatures when the grain size is small. Superplasticity appears when viscous grain boundary sliding is the dominant mechanism of plastic deformation. It was also reported that superplasticity occurs when a metal is deformed around the temperature of phase transformation.

\subsection{High Speed Superplasticity}

In most cases superplasticity appears at a low stain rate around $10^{-3} / \mathrm{sec}$. This means that one cycle of operation needs about $1000 \mathrm{sec}$ (15min) to deform the metal to a

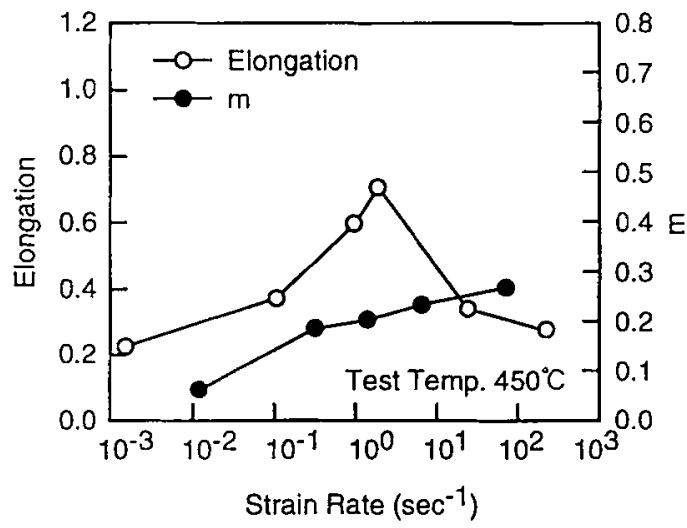

Fig.10 Elongation and strain rate sensitive index $m$ of mechanically alloyed aluminum alloy strain of 1.0. Because of this low productivity, superplastic forming is not used so much in the industry. To realize superplasticity at higher strain rates, some attempts have been made.

Since the peak of elongation shifts to higher strain rate as the grain size decreases, various methods were tried to reduce the grain size. One of the methods for obtaining extremely small grain size is mechanical alloying. An example of the process for mechanical alloying of $\mathrm{Al}-4.4 \mathrm{Cu}-2 \mathrm{Mg}$ is as follows: after charging metal powders in a water-cooled stainless steel pot together with $75 \%$ volume fraction of steel balls, the pot is oscillated by using a vibrating ball mill for about $30 \mathrm{~min}$, and then the powders are compacted and the compact is heated up to $500^{\circ} \mathrm{C}$ and extruded as a wire.

Fig. 10 [5] shows the elongation and $m$ value of mechanically alloyed $\mathrm{Al}-4.4 \mathrm{Cu}-2 \mathrm{Mg}$ in tension test at $450{ }^{\circ} \mathrm{C}$. The elongation peak exists at a strain rate of about $2 / \mathrm{sec}$. Since mechanical alloying takes a long time for preparing the material, it is not practical for ordinary manufacturing, and the aeronautical products are the main target.

\subsection{Isothermal Forging}

In the strain rate range of superplasticity, a very low forming load is possible by deforming the material at a slow deformation speed. A forging method with a low press speed was developed for forging refractory metals difficult to shape. In the forming process, not only the billet but also the tools are heated to the working temperature to prevent cooling of the billet during low speed deformation and the process is called "isothermal forging".

The frequently tested metals for isothermal forging are Ti-6Al-4V and IN100 (Ni base alloy). For forging of aluminum alloys, dies are sometimes heated although significant superplasticity may not be occur. Since the dies are heated to about $900^{\circ} \mathrm{C}$ ( $\mathrm{Ti}$ alloy) or 1050 ${ }^{\circ} \mathrm{C}$ ( $\mathrm{Ni}$ base alloy), the die steels which softens at around $600^{\circ} \mathrm{C}$ are not adequate. As for the die materials, some ceramics, $\mathrm{Ni}$ base alloys (for forging of $\mathrm{Ti}$ alloys) and Mo alloy (for forging of Ni base alloys) are considered to be suitable. But the dies made of these materials are extremely expensive and thus the finite element simulation is fully utilized to avoid trial and error procedures in die design. For the analysis of metal flow in isothermal forging, the rigid-plastic finite element which can accommodate strain rate sensitivity is used. Fig. 11 [6] shows an example of the simulated result of metal flow in isothermal forging. 


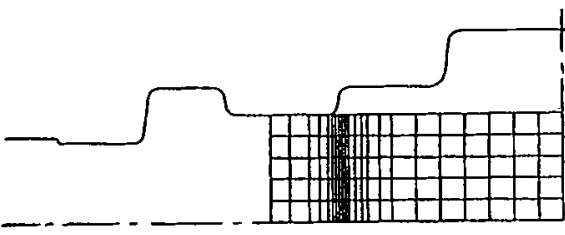

(a)

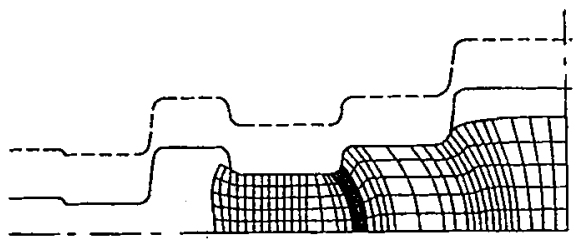

(c)

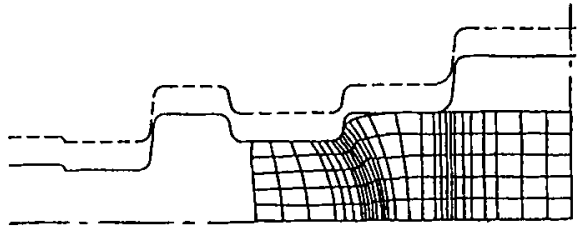

(b)

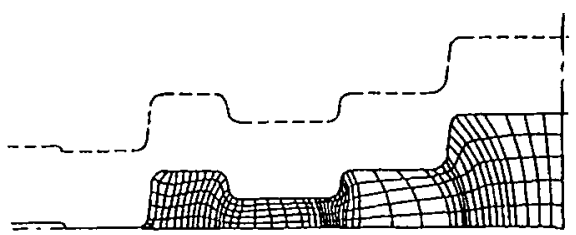

(d)

Fig.11 Deformation of grid in isothermal forging of Ti alloy simulated by rigid-plastic FEM

\section{CONCLUDING REMARKS}

Although the strain rate sensitivity of flow stress is an important factor for designing of processes and tools in metal forming, they are not studied much for practical purposes. The studies on strain rate effect is often considered too academic and cannot be used effectively in the practice. On the other hand, in the field of material testing, practical forming processes are not interested in and most of the collected data are irrelevant to the industry. If the data of the strain rate sensitivity are systematically collected in a form of data base, they can be used for computer simulation with the finite element method, and the results could be utilized effectively in the industry.

\section{REFERENCES}

[1] M.Oyane, F.Takashima, K.Osakada \& H.Tanaka: The Behavior of Some Steels under Dynamic Compression, The 10th Japan Congress on Testing Materials, (1967), 72 - 76.

[2] K.Osakada, J.Nakano \& K.Mori: Finite Element Method for Rigid-Plastic Analysis of Metal Forming - Formulation for Finite Deformation, Int. J.Mech.Sci., 24-8(1982), 459-468.

[3] K.Osakada et al.: Rigid-Plastic Finite Element Method for Impact and High Speed Deformation Problems, Int. J. Impact Engineering, 12-1(1992), 89-99.

[4] K.Higashi \& T.Sakai: Superplastic Behavior of Commercial Aluminum Bronze, Cino-Japan Joint Symposium on Superplasticity, (1985), 26-27.

[5] K.Shinagawa et al.: Superplasticity of Mechanically Alloyed Aluminum at High Strain Rate, Super Plasticity in Advanced Materials, (1991), Osaka, 581-586

[6] K.Ohuchi, S.Sasaki \& K.Matsuno: Isothermal Forging with Ceramic Dies on Industrial Basis, Proc.3rd Int. Conf. Tech. Plasticity, (1990),271-278. 